\title{
Overview of Adjuvant and Neoadjuvant Therapy for Resectable Gastric Cancer in the East
}

\author{
Kazumasa Fujitani \\ Department of Surgery, Osaka National Hospital, Osaka, Japan
}

\section{Key Words \\ Gastric cancer · Chemotherapy · Chemoradiotherapy}

\begin{abstract}
This review presents the current status of adjuvant and neoadjuvant treatment options for primary resectable gastric cancer in the East, with updated data from recent studies. Marked disparities between the East and the West in standard surgical procedures (D2 vs. D1/0 lymphadenectomy) and their outcomes result in significant geographical variation in preferred adjuvant treatments. Currently, oral fluoropyrimidine-based postoperative adjuvant chemotherapy, 1 year of S-1 chemotherapy, or capecitabine plus oxaliplatin for 6 months are the standards of care after curative resection with D2 lymphadenectomy for stage II/III gastric cancer in the East, though there is still some room for improvement. The role of postoperative adjuvant chemoradiotherapy (CRT) following curative D2 gastrectomy has long been debated in the East. However, the first prospective randomized controlled trial comparing CRT with chemotherapy alone failed to demonstrate a survival benefit, thus further studies are required. Chemotherapy has been pursued as a neoadjuvant approach in East Asia because of a rare locoregional recurrence after curative D2 gastrectomy. Locally advanced,
\end{abstract}

marginally resectable gastric cancer with poor prognosis, such as large type 3 or 4 tumors, para-aortic and/or bulky nodal disease, and serosa-positive gastric cancer, is the main target of neoadjuvant chemotherapy. Promising efficacy has been demonstrated in several phase II studies with the safe use of D2 or more extended surgery following neoadjuvant chemotherapy. Although the results of ongoing phase III trials are awaited, Asian findings could be relevant and generalizable to other regions when D2 surgery is performed by experienced surgeons.

Copyright $\odot 2013$ S. Karger AG, Basel

\section{Introduction}

In 2010, there were an estimated 989,600 new cases and more than 738,000 deaths from gastric cancer worldwide [1]. Gastric cancer is the fourth most common malignancy worldwide [2] and the second leading cause of cancer-related deaths [1], with the highest mortality rates reported in East Asia, including Japan, Korea, and China (28.1 per 100,000 males; 13.0 per 100,000 females) [3]. Approximately $60 \%$ of gastric cancers in the world are diagnosed in East Asia, with $41 \%$ of these in China and $11 \%$ in Japan [2].

\section{KARGER}

E-Mail karger@karger.com www.karger.com/dsu
C 2013 S. Karger AG, Basel

0253-4886/13/0302-0119\$38.00/0
Kazumasa Fujitani, MD

Department of Surgery, Osaka National Hospital

2-1-14 Hoenzaka, Chuo-ku

Osaka 540-006 (Japan)

E-Mail fujitani@onh.go.jp 
The 5-year survival rate for gastric cancer is $60 \%$ or higher in Japan and Korea, where over half of gastric cancer patients are diagnosed at an early stage. In contrast, gastric cancer is often diagnosed at an advanced stage in the majority of patients in the West, where approximately $50 \%$ of patients have metastasis at diagnosis; of those without metastasis at diagnosis, only $50 \%$ are eligible for gastric resection. Despite aggressive treatment, gastric cancer remains one of the most clinically challenging cancers in the West, with a suboptimal overall 5-year survival of $20-30 \%$ [4].

Surgery is the mainstay of treatment for resectable gastric cancer. Surgical resection of the primary tumor and regional lymph nodes is a key step in curative treatment. The extent of lymphadenectomy (D1 vs. D2) during gastrectomy for gastric cancer has been the subject of considerable debate over the past several decades. Two large randomized trials conducted in the West have so far failed to demonstrate the superiority of D2 dissection over D1 [5-7]. However, long-term follow-up results from a Dutch trial [8] have recently demonstrated significantly lower locoregional recurrence and gastric cancer-related death rates (D1:48\% vs. D2:37\%) with D2 dissection than D1 surgery after a median follow-up of 15.2 years. These results provide support for $\mathrm{D} 2$ dissection of gastric cancer, and D2 lymphadenectomy is now the recommended surgical procedure for patients with resectable gastric cancer worldwide, if performed safely by experienced surgeons. In Japan and Korea, D2 gastrectomy is the standard surgical procedure, with similar low postoperative morbidity and mortality rates and rare locoregional recurrence [9]. More frequent D2 lymph node dissection (in comparison to the West) contributes to a high overall survival (OS) rate of around 60\% in East Asia.

Even in East Asia, however, a sizable proportion of gastric cancer patients with stages II and III (moderately advanced) disease develop recurrence after curative D2 gastrectomy. Improved patient outcomes therefore require effective adjuvant treatments for resectable gastric cancer. Marked disparities between the East and the West in terms of surgery types and their outcomes result in large geographical variations in preferred adjuvant treatments. In East Asia, D2 surgical resection is followed by adjuvant oral fluoropyrimidine-based therapy $[10,11]$, whereas a perioperative approach with intensive combination chemotherapy given before and after surgery is conducted in the United Kingdom and parts of Europe [12], and adjuvant chemoradiotherapy (CRT) is commonly used following D0/1 surgery for patients with gastric cancer in the United States [13].
This review presents the current status of postoperative and preoperative adjuvant treatment options for primary resectable gastric cancer in the East, with updated data from recent studies.

\section{Rationale for Adjuvant Strategies in Gastric Cancer}

Despite radical surgery, quite a few patients undergoing curative resection relapse with local and systemic recurrence, which leads to poor OS. This recurrence is most likely due to occult micrometastases in the tumor bed and distant sites at the time of radical surgery. Multiple studies have evaluated strategies using chemotherapy, radiotherapy, or a combination of both in the adjuvant setting to eradicate these micrometastases, which have resulted in improved patient outcomes.

\section{Postoperative Adjuvant Therapy for Curatively Resected Gastric Cancer}

Although postoperative adjuvant chemotherapy is the current standard of care after curative surgical resection of gastric cancer in the East, various adjuvant therapies have been investigated over the last few decades in an attempt to prevent postoperative recurrence.

\section{Adjuvant Chemotherapy before the Pivotal Phase III \\ Trials \\ Meta-Analyses}

Multiple randomized, controlled studies have evaluated the role of postoperative adjuvant chemotherapy for gastric cancer. The majority of these trials were conducted in East Asia. Although many of the trials demonstrated negative results due to inappropriate patient selection, small sample sizes statistically underpowered for detection of difference in survival, and the use of suboptimal treatment regimens [14-16], a modest but significant survival benefit associated with postoperative adjuvant chemotherapy was demonstrated in several meta-analyses of patients with gastric cancer [17-20]. However, due to the heterogeneity of the populations and regimens used, there was no consensus about the chemotherapeutic regimen, schedule, or duration of treatment for adjuvant chemotherapy. Recently, a large meta-analysis of individual patient-level data from 17 randomized controlled trials $(\mathrm{n}=3,838)$ demonstrated an absolute survival benefit of $5.8 \%$ at 5 years and $7.4 \%$ at 10 years with postoperative adjuvant fluoropyrimidine-based chemotherapy when 
compared with surgery alone [ 55.3 vs. $49.6 \%$, hazard ratio (HR): 0.82, 95\% CI: 0.76-0.90] [21]. These meta-analyses demonstrated that adjuvant chemotherapy following curative surgery for gastric cancer continues to be an investigational approach, particularly in countries where D2 resection is not a routine surgical procedure.

\section{Uracil-Tegafur}

A prospective randomized trial by the National Surgical Adjuvant Study for Gastric Cancer (NSAS-GC) reported positive results with uracil-tegafur (UFT) [22]. Postoperative adjuvant chemotherapy with UFT (in a daily dose of $360 \mathrm{mg} / \mathrm{m}^{2}$ for 5 days every week) for 16 months demonstrated a significant improvement in both overall and relapse-free survival (RFS) over surgery alone (HR for OS: 0.48, 95\% CI: 0.26-0.89; HR for RFS: 0.44, 95\% CI: 0.25-0.79) in patients with serosa-negative, node-positive gastric cancer (T2 N1-2 tumors according to the Japanese classification of gastric carcinoma [23]) after curative gastrectomy with D2 or more extensive lymph node dissection. Of interest, the incidence of distant lymph node recurrence was significantly lower in the chemotherapy group, with no differences observed in other types of relapse such as hematogenous or peritoneal metastasis. However, the small sample size of the NSAS-GC study, with only 190 patients as opposed to the planned accrual of 500 patients, was considered insufficient to demonstrate a definitive advantage of adjuvant chemotherapy following D2 gastrectomy. Proof for the efficacy of adjuvant chemotherapy in gastric cancer had to wait for the more recent pivotal phase III trials that showed a definite survival benefit for curatively resected gastric cancer.

\section{Adjuvant Chemotherapy Established by Phase III Trials}

S-1

S-1, an oral anticancer drug composed of the 5-fluorouracil (5-FU) prodrug tegafur and two 5-FU modulators (5-chloro-2,4-dihydroxypyridine and oxonic acid), has achieved high response rates $(>40 \%)$ as a monotherapy in patients with advanced gastric cancer (AGC) in several phase II studies and has shown noninferiority to infusional 5-FU in a phase III trial for AGC [24]. Progressionfree survival and OS of patients with AGC treated by S-1 in that trial and another Japanese randomized trial conducted in the same period [25] were consistent at 4.0 and 4.2 months, and 11.0 and 11.4 months, respectively. Based on these findings, $\mathrm{S}-1$ is now considered to be one of the standard first-line regimens for AGC in Japan.

Adjuvant and Neoadjuvant Therapy for Resectable Gastric Cancer
The ACTS-GC (Adjuvant Chemotherapy Trial of S-1 for Gastric Cancer) study, a Japanese phase III study, was the first large-scale, prospective, randomized controlled trial of adjuvant chemotherapy, enrolling more than 1,000 patients who underwent curative $\mathrm{D} 2$ gastrectomy for gastric cancer [10]. This trial randomized 1,059 patients with histologically confirmed Japanese classification stage II, IIIA, or IIIB gastric cancer to surgery alone or a 1-year treatment with adjuvant S-1 monotherapy (in a daily dose of $80 \mathrm{mg} / \mathrm{m}^{2}$ given for $28 \mathrm{con}$ secutive days with 14 days of rest, repeated every 6 weeks). It demonstrated a significant $10.6 \%$ improvement in 5-year OS with adjuvant S-1 chemotherapy compared to surgery alone (71.7 vs. $61.1 \%$, HR: 0.669 , 95\% CI: $0.540-0.828$ ), as well as a $12.3 \%$ improvement in 5-year RFS compared to surgery alone ( 65.4 vs. $53.1 \%$, HR: 0.653 , 95\% CI: 0.537-0.793) [26]. Based on the results of the ACTS-GC study, postoperative adjuvant chemotherapy with S-1 is now widely accepted as a standard treatment throughout East Asia for treating patients with operable locally AGC.

\section{Capecitabine plus Oxaliplatin}

Capecitabine is a more globally accepted oral fluoropyrimidine agent than S-1 for the treatment of gastric cancer. Capecitabine's superiority to infusional 5-FU in terms of OS was shown in a meta-analysis of two phase III trials, REAL-2 [27] and ML17032 [28], against AGC [29]. Likewise, oxaliplatin's noninferiority to cisplatin for OS was proven in the REAL-2 study [27].

More recently, the CLASSIC (Capecitabine and Oxaliplatin Adjuvant Study in Stomach Cancer) trial, a large Korean phase III randomized controlled study undertaken in South Korea, China, and Taiwan, reported a significant benefit in disease-free survival (DFS) using adjuvant combination chemotherapy with capecitabine plus oxaliplatin (XELOX) following curative D2 gastrectomy compared to surgery alone [11]. This trial randomly assigned 1,035 patients with histologically confirmed Union for International Cancer Control (UICC) stage II, IIIA, or IIIB gastric adenocarcinoma to receive either adjuvant XELOX (capecitabine $1,000 \mathrm{mg} / \mathrm{m}^{2}$ twice daily on days $1-14$, every 3 weeks, and oxaliplatin $130 \mathrm{mg} / \mathrm{m}^{2}$ on day 1 , every 3 weeks) $\times 8$ cycles or surgery alone. Patients treated with adjuvant XELOX had significantly improved 3 -year DFS (74 vs. $59 \%$, HR: 0.56, 95\% CI: $0.44-0.72$ ) with a trend toward improved 3 -year OS rate $(83$ vs. $78 \%$, HR: $0.72,95 \%$ CI: $0.52-1.00)$ at a median follow-up of 34.2 months, although the data used for OS analysis have not been finalized at this point. The CLASSIC trial supports 
Table 1. Results of three randomized controlled trials of adjuvant chemotherapy conducted in East Asia

\begin{tabular}{|c|c|c|c|c|c|}
\hline Study & Patients, $\mathrm{n}$ & Stage & Treatment & HR for OS (95\% CI) & HR for RFS (95\% CI) \\
\hline ACTS-GC & 1,059 & II, IIIA, IIIB ${ }^{1}$ & S-1 for 1 year & $0.669(0.540-0.828)^{3}$ & $0.653(0.537-0.793)^{3}$ \\
\hline CLASSIC & 1,035 & II, IIIA, IIIB ${ }^{2}$ & XELOX $\times 8$ cycles ( 6 months) & $0.72(0.52-1.00)^{4}$ & $0.56(0.44-0.72)^{4,5}$ \\
\hline
\end{tabular}

${ }^{1}$ Japanese Classification of Gastric Carcinoma, ed. 2 (English). ${ }^{2}$ UICC-TNM Classification, ed. $6 .{ }^{3}$ At 5 years. ${ }^{4}$ At 3 years. ${ }^{5}$ DFS.

Table 2. Subgroup analysis of ACTS-GC [26] and CLASSIC [11]

\begin{tabular}{lll}
\hline Stage & $\begin{array}{l}\text { ACTS-GC } \\
\text { HR for 5-year OS }(95 \% \text { CI) }\end{array}$ & $\begin{array}{l}\text { CLASSIC } \\
\text { HR for 3-year DFS (95\% CI) }\end{array}$ \\
\hline II $^{1}$ & $0.509(0.338-0.765)$ & \\
IIIA $^{1}$ & $0.708(0.510-0.983)$ & \\
IIIB $^{1}$ & $0.791(0.520-1.205)$ & \\
\hline II $^{2}$ & $0.518(0.356-0.753)$ & $0.55(0.36-0.84)$ \\
IIIA $^{2}$ & $0.665(0.460-0.962)$ & $0.57(0.39-0.82)$ \\
IIIB $^{2}$ & $0.855(0.510-1.431)$ & $0.57(0.35-0.95)$ \\
\hline N0 $^{2}$ & $0.317(0.127-0.790)$ & $0.90(0.41-1.97)$ \\
$\mathrm{N}^{2}$ & $0.606(0.444-0.828)$ & $0.62(0.44-0.89)$ \\
$\mathrm{N}^{2}$ & $0.779(0.534-1.138)$ & $0.45(0.31-0.66)$ \\
$\mathrm{N}^{2}$ & $0.927(0.477-1.799)$ & \\
\hline
\end{tabular}

${ }^{1}$ Japanese Classification of Gastric Carcinoma, ed. 2 (English). ${ }^{2}$ UICC-TNM Classification, ed. 6.

the use of adjuvant XELOX as a new treatment option for patients with resectable gastric cancer after curative D2 gastrectomy.

Summary of the Results of Three Randomized

Controlled Trials of Adjuvant Chemotherapy

Conducted in East Asia

Table 1 summarizes the results of three randomized controlled clinical trials conducted in East Asia (ACTSGC [26], CLASSIC [11], and NSAS-GC [22]), all of which compared surgery alone to surgery with adjuvant chemotherapy (S-1, XELOX, and UFT) after curative D2 gastrectomy.

As shown in table 1, postoperative adjuvant chemotherapy with S-1 or XELOX reduced the risk of death by 33 and $28 \%$, respectively, both of which are comparable to the risk reduction of mortality of $26 \%$ obtained by postoperative CRT in the United States [13] or that of $25 \%$ obtained by perioperative triplet chemotherapy in the
United Kingdom [12]. However, disparities in surgical approach should be taken into consideration when comparing the efficacy of postoperative adjuvant treatments. D2 gastrectomy was performed on all patients enrolled in the Asian trials, whereas in the US study $90 \%$ of patients received suboptimal surgery $(\mathrm{D} 0 / 1)$ and in the UK trial less than half underwent D2 gastrectomy. It is of great concern whether postoperative CRT or perioperative triplet chemotherapy does in fact yield survival benefits after curative D2 gastrectomy.

Subgroup analysis of 5-year OS in the ACTS-GC study demonstrated insufficient efficacy of S-1 for stage IIIB gastric cancer (HR: 0.791, 95\% CI: 0.520-1.205) in contrast to a clear survival benefit of S-1 for stages II and IIIA disease (table 2) [26]. Subgroup analysis of 3-year DFS in the CLASSIC trial showed a consistent survival benefit for XELOX across all disease stages [11]. With respect to nodal disease, S-1 did not improve OS in patients with further nodal involvement (N2-3). Of note, XELOX failed to demonstrate survival benefit in N0 (T3N0/ T4N0) disease, which may suggest a weak point of XELOX therapy in patients at high risk for peritoneal relapse.

\section{Expected Pivotal Phase III Trial of Adjuvant Chemotherapy}

Another large prospective randomized controlled study, SAMIT (Stomach Cancer Adjuvant Multi-Institutional Trial), has completed accrual of 1,495 subjects in a $2 \times 2$ factorial design, with patients assigned to adjuvant fluoropyrimidine chemotherapy with UFT or S-1, or to sequential chemotherapy of paclitaxel (PTX) followed by UFT or S-1 [30]. Patients with serosa-positive gastric cancer $(\mathrm{T} 4 \mathrm{a} / 4 \mathrm{~b})$ with nodal metastases confined to the regional lymph nodes and without distant metastases after curative D2 gastrectomy were randomized to either UFT $267 \mathrm{mg} / \mathrm{m}^{2} /$ day for 4 weeks, every 4 weeks $\times 6$ cycles (arm A); S- $180 \mathrm{mg} / \mathrm{m}^{2} /$ day for 2 weeks, every 3 weeks $\times 8$ cycles (arm B); PTX $80 \mathrm{mg} / \mathrm{m}^{2}$ on days 1 and 8 for the first 3 
weeks $\times 1$ cycle, on days 1,8 , and 15 every 4 weeks $\times 2$ cycles, followed by UFT $267 \mathrm{mg} / \mathrm{m}^{2} /$ day for 4 weeks, every 4 weeks $\times 3$ cycles ( $\operatorname{arm~C)}$, or PTX as in arm C, followed by S-1 $80 \mathrm{mg} / \mathrm{m}^{2} /$ day for 2 weeks, every 3 weeks $\times$ 4 cycles (arm D). The fluoropyrimidine cycles were extended for an additional 24 weeks in 2007 after publication of the ACTS-GC study in which the adjuvant S- 1 was given for 12 months. PTX had been generally regarded in Japan as effective against peritoneal metastases due to its unique pharmacokinetics and was expected in the adjuvant setting to prevent relapse such as peritoneal carcinomatosis among patients with serosa-positive cancer. This study therefore aimed to determine the role of sequential use of PTX followed by oral fluoropyrimidines in comparison with fluoropyrimidines alone, as well as to identify which of the two oral fluoropyrimidines, UFT or S-1, was preferred in an adjuvant setting for curatively resected gastric cancer. DFS, a primary endpoint, will be presented in 2013.

\section{Phase III Trials of Intraperitoneal Administration as}

\section{Adjuvant Chemotherapy}

The most frequent mode of recurrence and cause of subsequent cancer death in serosa-positive gastric cancer is peritoneal metastasis, even after curative resection. To prevent such distant recurrences and increase the potential of cure, intraperitoneal administration of cytotoxic agents with systemic chemotherapy has been attempted in patients with macroscopically serosa-positive (T3-4) gastric cancer after curative D2 gastrectomy.

A Japanese multicenter, prospective, randomized controlled phase III clinical trial [31] randomized 268 patients to surgery alone or adjuvant chemotherapy consisting of intraperitoneal cisplatin $\left(70 \mathrm{mg} / \mathrm{m}^{2}\right)$ at the time of surgery as well as intravenous cisplatin $\left(70 \mathrm{mg} / \mathrm{m}^{2}\right)$ on postoperative day 14 and $5-\mathrm{FU}\left(700 \mathrm{mg} / \mathrm{m}^{2}\right)$ on days $14-$ 16 , followed by daily oral UFT $\left(267 \mathrm{mg} / \mathrm{m}^{2}\right)$ for 12 months No survival benefit in 5-year OS (62.0\% adjuvant chemotherapy vs. $60.9 \%$ surgery alone) or 5 -year RFS (57.5\% adjuvant chemotherapy vs. $55.6 \%$ surgery alone) was obtained from adjuvant chemotherapy. It also was associated with an unexpectedly low completion rate of $38.5 \%$.

A Korean phase III trial [32] randomly assigned 521 patients with serosa-positive gastric cancer following curative resection to two different types of adjuvant chemotherapy. The MFP group received intraperitoneal cisplatin (100 mg) during surgery followed by intravenous mitomycin-C $\left(15 \mathrm{mg} / \mathrm{m}^{2}\right)$ on postoperative day 1 , and oral doxifluridine (460-600 mg/m²/day) for 12 months with six injections of monthly cisplatin $\left(60 \mathrm{mg} / \mathrm{m}^{2}\right)$. The
Mf group received two injections of infusional mitomycin-C $\left(20 \mathrm{mg} / \mathrm{m}^{2}\right) 3-6$ weeks after surgery, and another 3 months of injections of oral doxifluridine beginning 4 weeks after the last mitomycin-C. The MFP group showed a significantly longer OS (HR: $0.77,95 \%$ CI: $0.60-0.98$ ) and RFS (HR: 0.73, 95\% CI: 0.57-0.93) than the Mf group. However, this study does not fully clarify whether intraperitoneal cisplatin contributes definitively to improved survival.

\section{Adjuvant CRT Not Yet Established by Phase III Trials}

Although postoperative CRT is currently widely used in the Unites States as the standard of care for patients with resected gastric cancer based on the results of the Intergroup 0116 study [13], the Asian and European interpretation of this study is that the addition of adjuvant CRT compensated for the suboptimal D0/1 surgical resection performed in $90 \%$ of the enrolled patients [33, 34]. In contrast, whether postoperative adjuvant CRT benefits patients after optimal gastric surgery with $\mathrm{D} 2$ lymphadenectomy has long been a matter of debate in Japan and Korea, where a low incidence of locoregional recurrence is observed after D2 gastrectomy. A Korean retrospective analysis suggested a potential survival benefit from adjuvant CRT after D2 gastrectomy with a 5 -year OS rate of $57 \%$ for CRT versus $51 \%$ for surgery alone [35].

More recently, ARTIST (Adjuvant Chemoradiation Therapy in Stomach Cancer Trial), a Korean single-center phase III prospective randomized controlled study, investigated for the first time the role of postoperative adjuvant CRT following curative gastrectomy with D2 or more extended lymphadenectomy [36]. This study randomized 458 patients to the XP arm (capecitabine 2,000 $\mathrm{mg} / \mathrm{m}^{2}$ per day on days $1-14$ and cisplatin $60 \mathrm{mg} / \mathrm{m}^{2}$ on day 1 , repeated every 3 weeks, for 6 cycles) or to the XP/ XRT/XP arm ( 2 cycles of XP followed by 45-Gy irradiation with concurrent capecitabine $1,650 \mathrm{mg} / \mathrm{m}^{2}$ per day for 5 weeks, and 2 additional cycles of XP). The addition of XRT to XP chemotherapy failed to prolong 3-year DFS (78.2\% in the XP/XRT/XP arm vs. $74.2 \%$ in the XP arm; $\mathrm{p}=0.0862$ ), although the XP/XRT/XP arm demonstrated superior 3-year DFS compared with XP alone (HR: $0.6865,95 \%$ CI: $0.4735-0.9952)$ in a subgroup analysis of 396 patients with pathologically positive lymph nodes.

Of note, there were no significant differences between the treatment arms in ARTIST in terms of the incidences of locoregional recurrence ( $8.3 \%$ in the XP arm vs. $4.8 \%$ in the XP/XRT/XP arm; $\mathrm{p}=0.3533$ ) and distant metastases $(24.6 \%$ in the XP arm vs. $20.4 \%$ in the XP/XRT/XP 
arm; $p=0.5568)$. These findings are in accordance with those of a recent Dutch retrospective study that compared patients treated in the Dutch Gastric Cancer Group trial (who underwent only surgery) with those treated in several Dutch phase I/II studies with postoperative fluoropyrimidine-based CRT [37] and showed a significant association between postoperative CRT use and improved local control after D1 but not D2 dissection [37]. Therefore, it is currently difficult to draw any conclusions regarding the benefit of postoperative adjuvant CRT administered after curative D2 gastrectomy, and this will likely remain the case until a subsequent phase III trial (ARTIST-II) focusing on pathologic lymph node-positive disease alone is performed.

\section{Neoadjuvant Therapy for Potentially Resectable Gastric Cancer}

Neoadjuvant multimodal approaches are based on either chemotherapy, to improve systemic disease control, and/or radiotherapy, which basically aims to improve local tumor control, thereby improving patient outcomes.

Neoadjuvant therapy may theoretically be superior to postoperative treatment for several reasons. First, neoadjuvant therapy potentially leads to downsizing or downstaging of the tumor and may therefore substantially facilitate its complete resection, which is the cornerstone of cure in oncological surgery. Second, neoadjuvant chemotherapy is the earliest means of eliminating systemic micrometastases, which in many cases are the cause of poor prognoses. Third, neoadjuvant chemotherapy can be used to assess tumor chemosensitivity to cytotoxic medications. Fourth, chemotherapy delivery may be more efficient if given prior to surgical disruption of the vasculature. Furthermore, pr eoperative treatment of gastric cancer is generally better tolerated than postoperative treatment. Decreased treatment compliance due to increased gastrointestinal toxicities such as nausea and vomiting was observed in the postoperative arm compared to the preoperative arm of studies in which the same chemotherapy regimen was given perioperatively $[12,38]$.

A rapid, robust response and relatively low toxicity are required for neoadjuvant therapy because target tumors are resectable or marginally resectable and patients must receive potentially curative surgery after preoperative treatment.

\section{Neoadjuvant Treatment in East Asia}

In East Asia, where sole locoregional failure is found in only $8.5-13.4 \%$ of patients and the remainder of relapsed patients experience distant failure $[11,26]$ after curative $\mathrm{D} 2$ gastrectomy, chemotherapy is actively pursued as the main neoadjuvant approach. The benefit of neoadjuvant treatment followed by D2 surgery has yet to be confirmed [39], though Western trials have favored the neoadjuvant approach with suboptimal (D0/1) surgery $[12,38]$. Now that $\mathrm{D} 2$ gastrectomy is the standard of care in both Europe [40] and the United States [41], Asian findings could be highly relevant for, and might be generalizable to, other regions when D2 surgery is performed by experienced surgeons.

\section{Targets of Neoadjuvant Chemotherapy}

Neoadjuvant chemotherapy is a rising option for locally advanced, marginally resectable gastric cancer. More than half of locally advanced large type $3(\geq 8 \mathrm{~cm})$ or 4 (linitis plastica) tumors metastasize to the peritoneum with a historical 3-year OS rate of $15 \%$, even when the entire tumor is resected with curative intent, suggesting the microscopic peritoneal seeding of cancer cells that remain undetected during surgery. Likewise, para-aortic lymph node metastases $(\geq 1 \mathrm{~cm})$ and/or bulky nodal metastases $(\geq 3 \mathrm{~cm}$ or $\geq 1.5 \mathrm{~cm} \times \geq 2$ nodes) surrounding the celiac artery and its branches are considered marginally resectable due to their extremely poor historical 3-year OS rate of 10\% despite complete resection of the entire tumor with curative intent, suggesting the presence of distant micrometastases uncontrollable by surgery plus postoperative chemotherapy. Additional therapy besides curative resection should be developed to improve these dismal prognoses.

The Japan Clinical Oncology Group (JCOG) has conducted a series of prospective multi-institutional phase II/ III trials of neoadjuvant chemotherapy for these patients (table 3).

\section{Large Type 3 or 4 (Linitis Plastica) Gastric Cancer}

The JCOG 0210 study evaluated the safety and efficacy of preoperative chemotherapy with S-1 plus cisplatin for clinically resectable large type 3 or type 4 gastric cancer in a phase II setting. Fifty patients received two 28 -day cycles of oral S-1 (80-120 mg/body, days 1-21) and infusional cisplatin $\left(60 \mathrm{mg} / \mathrm{m}^{2}\right.$, day 8$)$, and 36 of the patients (73\%, 95\% CI: 59-85\%) underwent curative resection (R0 resection) with D2 or more extended lymph node dissection. One treatment-related death was observed during the first course of chemotherapy due to uncontrollable hemorrhaging from the primary tumor $(2 \%, 95 \% \mathrm{CI}$ : 
Table 3. Results of three prospective phase II trials of neoadjuvant chemotherapy in Japan [42-44]

\begin{tabular}{|c|c|c|c|}
\hline \multirow{3}{*}{$\begin{array}{r}\text { Target: } \\
\text { Regimen: }\end{array}$} & \multirow{3}{*}{$\begin{array}{l}\text { JCOG } 0210 \\
\text { large type } \\
3 / 4 \\
\text { S-1+ } \\
\text { cisplatin }\end{array}$} & \multirow{2}{*}{$\begin{array}{l}\text { JCOG } 0001 \\
\text { para-aortic/ } \\
\text { bulky nodal dis }\end{array}$} & \multirow{2}{*}{$\begin{array}{l}\text { JCOG } 0405 \\
\text { sease }\end{array}$} \\
\hline & & & \\
\hline & & $\begin{array}{l}\text { irinotecan + } \\
\text { cisplatin }\end{array}$ & $\begin{array}{l}\text { S-1+ } \\
\text { cisplatin }\end{array}$ \\
\hline Delivered courses, $\mathrm{n}$ & 2 & $2-3$ & $2-3$ \\
\hline Enrolled patients, n & 50 & 55 & 51 \\
\hline Response rate, \% & & 55 & 63 \\
\hline R0 resection, \% & 73 & 65 & 82 \\
\hline $\mathrm{pCR}, \%$ & 2 & 0 & 2 \\
\hline Grade $1 \mathrm{~b}$ or higher, $\%$ & 48 & 15 & 51 \\
\hline $\mathrm{TRD}, \mathrm{n}$ & 1 & 3 & 0 \\
\hline 3-year OS reference, \% & 15 & 10 & \\
\hline 3-year OS, \% & 26 & 27 & 59 \\
\hline
\end{tabular}

$\mathrm{pCR}=$ Pathological complete response TRD = treatment-related death; 3-year OS = 3-year overall survival.

0.1-11). Median survival time was 17.3 months (95\% CI: 15.1-23.8) and the 3-year OS rate was $26.0 \%$ (95\% CI: 14.9-38.6). Pathological response, defined as the disappearance, degeneration, or necrosis of more than one third of the primary tumor (grade $1 \mathrm{~b}$ or higher), was confirmed in 24 patients $(48 \%)$, with one complete response (no residual tumor; 2\%, 95\% CI: 0.1-11). Postoperative morbidity included pancreatic leakage in 4 patients, intraperitoneal abscess in 3 , pneumonia in 2 , and wound infection in 3, with no postoperative mortality [42].

Based on the promising results of the JCOG 0210 study, the JCOG 0501 phase III study is now underway, targeting the same population with OS as a primary endpoint. The study plans to enroll 316 patients who have no or minimal peritoneal lesions adjacent to the stomach irrespective of the presence of peritoneal free cancer cells during laparoscopic exploration. Participants have been randomized to two courses of neoadjuvant chemotherapy with S-1 plus cisplatin followed by D2 or more extended surgery, or surgery alone (fig. 1). In both arms, 1 year of S-1 monotherapy will be delivered postoperatively. This study is the first Japanese prospective randomized controlled trial of neoadjuvant chemotherapy for resectable gastric cancer and is expected to be a landmark study, determining the future direction for neoadjuvant chemotherapy in Japan.

\section{Para-Aortic and/or Bulky Nodal Disease}

JCOG has carried out two prospective phase II trials (JCOG 0001 and 0405) for gastric cancer patients with

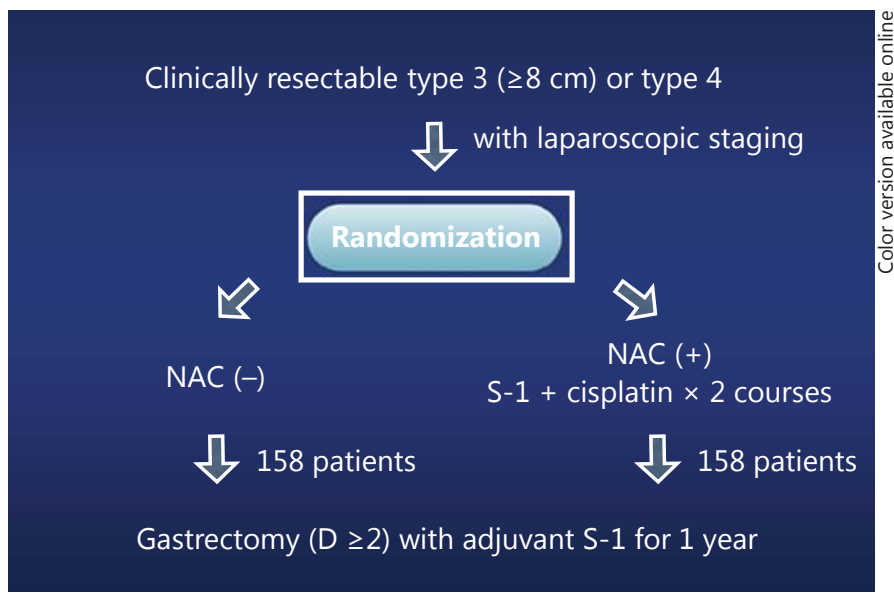

Fig. 1. JCOG 0501 study. NAC = Neoadjuvant chemotherapy.

para-aortic lymph node metastases and/or bulky nodal metastases surrounding the celiac artery and its branches. In both trials, the absence of peritoneal dissemination along with negative lavage cytology had to be confirmed by staging laparoscopy before study entry.

The JCOG 0001 study explored the efficacy and safety of two or three 4-week cycles of induction chemotherapy with irinotecan $\left(70 \mathrm{mg} / \mathrm{m}^{2}\right.$ on days 1 and 15) and cisplatin $\left(80 \mathrm{mg} / \mathrm{m}^{2}\right.$ on day 1$)$ followed by extended gastrectomy with D2 plus para-aortic nodal dissection in 55 patients. Clinical response to chemotherapy was observed in 30 patients. R0 resection was carried out in $65 \%$ (95\% CI: 51-78) of the patients, with a pathological response (grade $1 \mathrm{~b}$ or higher) in $15 \%$ (95\% CI: 7-27). Median survival time was 14.6 months (95\% CI: 10.1-24.1) and the 3-year OS rate was $27 \%$ (95\% CI: $15-39$ ). There were three treatment-related deaths (5.5\%, 95\% CI: $1.0-15)$, in 2 cases due to myelosuppression during chemotherapy and in 1 case due to postoperative complications. Surgical complications included anastomotic leakage in 1 patient, pancreatic fistula in 6 , abdominal abscess in 2 , pneumonia in 2 , and wound infection in 2 [43].

The JCOG 0405 study enrolled 51 patients who received two or three 4-week cycles of neoadjuvant chemotherapy with oral S-1 (80-120 mg/body, days 1-21) and cisplatin $\left(60 \mathrm{mg} / \mathrm{m}^{2}\right.$, day 8$)$, followed by extended gastrectomy with D2 plus para-aortic nodal dissection. A clinical response was observed in 32 patients (62.8\%, 95\% CI: 48.1-75.9). Forty-seven patients underwent surgery, with R0 resection performed in 42 of them (82.4\%, 95\% CI: 69.1-91.6). Pathological response (grade $1 \mathrm{~b}$ or higher) was confirmed in 26 patients (51.0\%, 95\% CI: 36.6-65.3), with one complete 


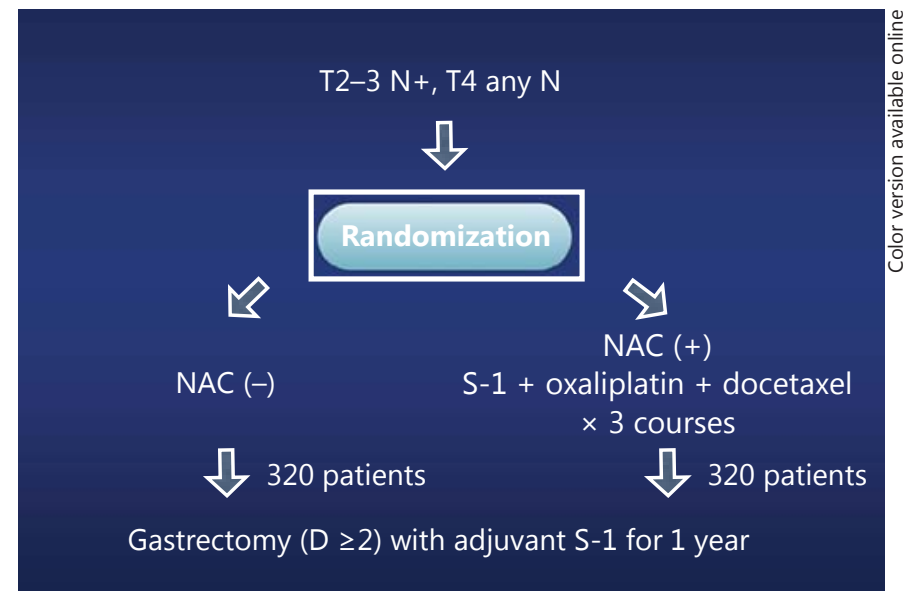

Fig. 2. PRODIGY study. NAC = Neoadjuvant chemotherapy.

response (2\%). The 3-year OS rate was 58.8\% (95\% CI: 44.1-70.9), with no treatment-related deaths. Postoperative complications included anastomotic leakage in 3 patients, pancreatic fistula in 11 , abdominal abscess in 8 , pneumonia in 2, and deep vein thrombosis in 2 [44].

Neoadjuvant S-1 plus cisplatin followed by D2 plus para-aortic lymphadenectomy demonstrated an excellent 3 -year OS rate of $58.8 \%$, which was far better than expected in this marginally resectable population. Even after adjusting for baseline factors between the JCOG 0001 and 0405 studies, S-1 plus cisplatin was shown by multivariate analysis to be superior to irinotecan plus cisplatin in terms of OS (HR: 0.335, 95\% CI: 0.184-0.612) [45]. In addition, a remarkable interaction between treatment and status of lymph node metastases was observed, pointing out the poor prognosis and necessity of further treatment improvement in patients having both para-aortic and bulky nodal involvement [45]. Based on these findings, JCOG has launched a novel phase II study (JCOG 1002) that employs a triple combination regimen for the same population. Patients receive two or three 4-week cycles of neoadjuvant chemotherapy with oral S-1 (80-120 $\mathrm{mg} /$ body, days 1-14) and intravenous cisplatin (60 mg/ $\left.\mathrm{m}^{2}\right)$ and docetaxel $\left(40 \mathrm{mg} / \mathrm{m}^{2}\right)$ on day 1 , followed by extended surgery with D2 plus para-aortic nodal dissection.

\section{Serosa-Positive (T4a/b) Gastric Cancer}

More than half of serosa-positive gastric cancers recur even after macroscopic complete resection with curative intent. Several multicenter phase II studies have explored the efficacy and safety of neoadjuvant chemotherapy for clinically serosa-positive (T4a/b) gastric cancer.
One course of S-1 (80-120 mg/body, days 1-21) plus cisplatin $\left(60 \mathrm{mg} / \mathrm{m}^{2}\right.$, day 8$)$ followed by D2 or more extended gastrectomy resulted in an R0 resection rate of $78 \%$ (38 of 49 patients), with a pathological response (grade $1 \mathrm{~b}$ or higher) in 39\%. Postoperative morbidity and mortality rates were 10.2 and $0 \%$, respectively [46].

Two or four 3-week cycles of neoadjuvant chemotherapy with oral S-1 (80-120 mg/body, days 1-14) and intravenous cisplatin $\left(60 \mathrm{mg} / \mathrm{m}^{2}\right)$ and docetaxel $\left(60 \mathrm{mg} / \mathrm{m}^{2}\right)$ on day 8 , followed by standard D2 gastrectomy, demonstrated a high $\mathrm{R} 0$ resection rate of $90 \%$ (36 of 40 patients), with a pathological response (grade $1 \mathrm{~b}$ or higher) of $60 \%$. Postoperative morbidity and mortality rates were 22.5 and $0 \%$, respectively [47].

Four or six 3-week cycles of neoadjuvant chemotherapy with oral capecitabine $\left(1,875 \mathrm{mg} / \mathrm{m}^{2}\right.$, days $\left.1-14\right)$ and cisplatin $\left(60 \mathrm{mg} / \mathrm{m}^{2}\right)$ and docetaxel $\left(60 \mathrm{mg} / \mathrm{m}^{2}\right)$ on day 1 , followed by $\mathrm{D} 2$ gastrectomy, resulted in a high $\mathrm{R} 0$ resection rate of $71 \%$ ( 15 of 21 patients), with a high rate of pathological complete response (4 of 21 patients, 19\%). Surgical morbidity and mortality rates were 11.1 and $0 \%$, respectively [48].

It is difficult to compare these studies because of differences in the clinical definitions of serosa-positive $(\mathrm{T} 4 \mathrm{a} / \mathrm{b})$ gastric cancer. The most accurate clinical TNM staging must be worked out so that the optimal stagedependent strategies of neoadjuvant treatment can be established.

In addition to these phase II studies, a novel phase III trial (PRODIGY) is ongoing in which 640 patients with T2-3 N+ or T4 tumors are being randomized to three 3-week cycles of neoadjuvant chemotherapy with oral S-1 (80-120 mg/body, days 1-14) and intravenous oxaliplatin $\left(100 \mathrm{mg} / \mathrm{m}^{2}\right)$ and docetaxel $\left(50 \mathrm{mg} / \mathrm{m}^{2}\right)$ on day 1 , followed by standard D2 gastrectomy, or surgery alone (fig. 2). In both arms, S-1 monotherapy is given for 1 year postoperatively. This could become a landmark study, resulting in a paradigm shift in the standard treatment for a wide range of potentially curatively resectable AGC in the East.

\section{Neoadjuvant CRT}

Although neoadjuvant CRT generally achieves superior local tumor control compared to neoadjuvant chemotherapy, clinical trials of neoadjuvant CRT have rarely been performed in the East. As a result, its safety and efficacy for locally AGC remain unclear, especially when it is followed by $\mathrm{D} 2$ gastrectomy.

A small preliminary prospective study of 12 patients with Japanese stage IIIB gastric cancer (T4N1M0 or 
T3N2M0) was recently reported [49]. Patients received oral S-1 (65 mg/m²/day) with concurrent $50-$ Gy radiotherapy followed by radical D2 surgery. The chemotherapy and radiotherapy completion rates were 83.3 and $100 \%$, respectively. Eleven of 12 patients (91.7\%) underwent $\mathrm{R} 0$ resection, with operative morbidity and mortality rates of 16.7 and $0 \%$, respectively. A remarkably high pathologic response (grade $1 \mathrm{~b}$ or higher) rate of $83.3 \%$ was obtained, with a complete response in $8.3 \%$ of patients. However, in contrast to the impressive pathologic response in the primary tumor, the response in metastatic nodes appeared to be relatively low in this study. This treatment approach is expected to be tested in a large clinical trial for locally advanced disease featuring adjacent tissue invasion (T4 tumor).

\section{Conclusion}

Given the current variation in the treatment of operable gastric cancer across the world, it is difficult to simply extrapolate successful Eastern strategies to the West. However, recent standardization of D2 lymph node dissection worldwide will facilitate international studies in both the East and West, with the goal of increasing therapeutic efficacy and improving the poor prognosis of this aggressive disease.

\section{References}

-1 Jemal A, Siegel R, Xu J, Ward E: Cancer statistics, 2010. CA Cancer J Clin 2010;60:277300.

-2 Kamangar F, Dores GM, Anderson WF: Patterns of cancer incidence, mortality, and prevalence across five continents: defining priorities to reduce cancer disparities in different geographic regions of the world. J Clin Oncol 2006;24:2137-2150.

3 Ferlay J, Shin HR, Bray F, Forman D, Mathers C, Parkin DM: Globocan 2008: Cancer Incidence and Mortality Worldwide: IARC CancerBase No. 10. Lyon, International Agency for Research on Cancer, 2010. http://www. iarc.fr/en/publications/eresources/cancerbases/index.php.

-4 Van Cutsem E, Dicato M, Geva R, Arber N, Bang Y, Benson A, Cervantes A, Diaz-Rubio E, Ducreux M, Glynne-Jones R, Grothey A, Haller D, Haustermans K, Kerr D, Nordlinger B, Marshall J, Minsky BD, Kang YK, Labianca R, Lordick F, Ohtsu A, Pavlidis N, Roth A, Rougier P, Schmoll HJ, Sobrero A, Tabernero J, Van de Velde C, Zalcberg J: The diagnosis and management of gastric cancer: expert discussion and recommendations from the 12th ESMO/World Congress on Gastrointestinal Cancer, Barcelona, 2010. Ann Oncol 2011; 22(suppl 5):v1-v9.

$\checkmark 5$ Cuschieri A, Weeden S, Fielding J, Bancewicz J, Craven J, Joypaul V, Sydes M, Fayers P: Patient survival after D1 and D2 resections for gastric cancer: long-term results of the MRC randomized surgical trial. Surgical Co-operative Group. Br J Cancer 1999;79:1522-1530.

-6 Bonenkamp JJ, Hermans J, Sasako M, van de Velde CJ, Welvaart K, Songun I, Meyer S, Plukker JT, Van Elk P, Obertop H, Gouma DJ, van Lanschot JJ, Taat CW, de Graaf PW, von Meyenfeldt MF, Tilanus H, Dutch Gastric
Cancer Group: Extended lymph-node dissection for gastric cancer. N Engl J Med 1999; 340:908-914.

$>7$ Hartgrink $\mathrm{HH}$, van de Velde CJ, Putter H, Bonenkamp JJ, Klein Kranenbarg E, Songun I, Welvaart K, van Krieken JH, Meijer S, Plukker JT, van Elk PJ, Obertop H, Gouma DJ, van Lanschot JJ, Taat CW, de Graaf PW, von Meyenfeldt MF, Tilanus H, Sasako M: Extended lymph node dissection for gastric cancer: who may benefit? Final results of the randomized Dutch Gastric Cancer Group trial. J Clin Oncol 2004;22:2069-2077.

-8 Songun I, Putter H, Kranenbarg EM, Sasako $\mathrm{M}$, van de Velde CJ: Surgical treatment of gastric cancer: 15-year follow-up results of the randomised nationwide Dutch D1D2 trial. Lancet Oncol 2010;11:439-449.

-9 Sano T, Sasako M, Yamamoto S, Nashimoto A, Kurita A, Hiratsuka M, Tsujinaka T, Kinoshita T, Arai K, Yamamura Y, Okajima $\mathrm{K}$ : Gastric cancer surgery: morbidity and mortality results from a prospective randomized controlled trial comparing D2 and extended para-aortic lymphadenectomy - Japan Clinical Oncology Group study 9501. J Clin Oncol 2004;22:2767-2773.

$>10$ Sakuramoto S, Sasako M, Yamaguchi T, Kinoshita T, Fujii M, Nashimoto A, Furukawa $\mathrm{H}$, Nakajima $\mathrm{T}$, Ohashi $\mathrm{Y}$, Imamura $\mathrm{H}, \mathrm{Hi}$ gashino M, Yamamura Y, Kurita A, Arai K, ACTS-GC Group: Adjuvant chemotherapy for gastric cancer with S-1, an oral fluoropyrimidine. N Engl J Med 2007;357:1810-1820.

11 Bang YJ, Kim YW, Yang HK, Chung HC, Park YK, Lee KH, Lee KW, Kim YH, Noh SI, Cho JY, Mok YJ, Kim YH, Ji J, Yeh TS, Button P, Sirzén F, Noh SH, CLASSIC Trial Investigators: Adjuvant capecitabine and oxaliplatin for gastric cancer after D2 gastrectomy
(CLASSIC): a phase 3 open-label, randomised controlled trial. Lancet 2012;379:315-321.

12 Cunningham D, Allum WH, Stenning SP, Thompson JN, Van de Velde CJ, Nicolson M, Scarffe JH, Lofts FJ, Falk SJ, Iveson TJ, Smith DB, Langley RE, Verma M, Weeden S, Chua YJ, MAGIC Trial Participants: Perioperative chemotherapy versus surgery alone for resectable gastroesophageal cancer. $\mathrm{N}$ Engl J Med 2006;355:11-20.

13 Macdonald JS, Smalley SR, Benedetti J, Hundahl SA, Estes NC, Stemmermann GN, Haller DG, Ajani JA, Gunderson LL, Jessup JM, Martenson JA: Chemoradiotherapy after surgery compared with surgery alone for adenocarcinoma of the stomach or gastroesophageal junction. N Engl J Med 2001;345:725-730.

14 Nakajima T, Takahashi T, Takagi K, Kuno K, Kajitani T: Comparison of 5-fluorouracil with ftorafur in adjuvant chemotherapies with combined inductive and maintenance therapies for gastric cancer. J Clin Oncol 1984;2: 1366-1371

15 Nakajima T, Nashimoto A, Kitamura M, Kito T, Iwanaga T, Okabayashi K, Goto M: Adjuvant mitomycin and fluorouracil followed by oral uracil plus tegafur in serosa-negative gastric cancer: a randomised trial. Gastric Cancer Surgical Study Group. Lancet 1999;354:273-277.

16 Nashimoto A, Nakajima T, Furukawa H, Kitamura M, Kinoshita T, Yamamura Y, Sasako M, Kunii Y, Motohashi H, Yamamoto S, Gastric Cancer Surgical Study Group, Japan Clinical Oncology Group: Randomized trial of adjuvant chemotherapy with mitomycin, fluorouracil, and cytosine arabinoside followed by oral fluorouracil in serosa-negative gastric cancer: Japan Clinical Oncology Group 9206-1. J Clin Oncol 2003;21:22822287. 
17 Earle CC, Maroun JA: Adjuvant chemotherapy after curative resection for gastric cancer in non-Asian patients: revisiting a meta-analysis of randomised trials. Eur J Cancer 1999;35: 1059-1064.

- 18 Mari E, Floriani I, Tinazzi A, Buda A, Belfiglio M, Valentini M, Cascinu S, Barni S, Labianca $\mathrm{R}$, Torri V: Efficacy of adjuvant chemotherapy after curative resection for gastric cancer: a meta-analysis of published randomised trials. A study of the GISCAD (Gruppo Italiano per lo Studio dei Carcinomi dell'Apparato Digerente). Ann Oncol 2000;11:837-843.

19 Panzini I, Gianni L, Fattori PP, Tassinari D, Imola M, Fabbri P, Arcangeli V, Drudi G, Canuti D, Fochessati F, Ravaioli A: Adjuvant chemotherapy in gastric cancer: a meta-analysis of randomized trials and a comparison with previous meta-analyses. Tumori 2002; 88:21-27.

20 Janunger KG, Hafström L, Glimelius B: Chemotherapy in gastric cancer: a review and updated meta-analysis. Eur J Surg 2002;168: 597-608.

-21 GASTRIC (Global Advanced/Adjuvant Stomach Tumor Research International Collaboration) Group, Paoletti X, Oba K, Burzykowski T, Michiels S, Ohashi Y, Pignon JP, Rougier P, Sakamoto J, Sargent D, Sasako M, Van Cutsem E, Buyse M: Benefit of adjuvant chemotherapy for resectable gastric cancer: a meta-analysis. JAMA 2010;303:17291737.

-22 Nakajima T, Kinoshita T, Nashimoto A, Sairenji M, Yamaguchi T, Sakamoto J, Fujiya T, Inada T, Sasako M, Ohashi Y, National Surgical Adjuvant Study of Gastric Cancer Group: Randomized controlled trial of adjuvant uracil-tegafur versus surgery alone for serosa-negative, locally advanced gastric cancer. Br J Surg 2007;94:1468-1476.

23 Japanese Gastric Cancer Association: Japanese Classification of Gastric Carcinoma 2nd English Edition. Gastric Cancer 1998;1: $10-24$.

24 Boku N, Yamamoto S, Fukuda H, Shirao K, Doi T, Sawaki A, Koizumi W, Saito H, Yamaguchi K, Takiuchi H, Nasu J, Ohtsu A, Gastrointestinal Oncology Study Group of the Japan Clinical Oncology Group: Fluorouracil versus combination of irinotecan plus cisplatin versus S-1 in metastatic gastric cancer: a randomised phase 3 study. Lancet Oncol 2009;10: 1063-1069.

-25 Koizumi W, Narahara H, Hara T, Takagane A, Akiya T, Takagi M, Miyashita K, Nishizaki T, Kobayashi O, Takiyama W, Toh Y, Nagaie T, Takagi S, Yamamura Y, Yanaoka K, Orita H, Takeuchi M: S-1 plus cisplatin versus S-1 alone for first-line treatment of advanced gastric cancer (SPIRITS trial): a phase III trial. Lancet Oncol 2008;9:215-221.

-26 Sasako M, Sakuramoto S, Katai H, Kinoshita T, Furukawa H, Yamaguchi T, Nashimoto A, Fujii M, Nakajima T, Ohashi Y: Five-year outcomes of a randomized phase III trial comparing adjuvant chemotherapy with S-1 ver- sus surgery alone in stage II or III gastric cancer. J Clin Oncol 2011;29:4387-4393.

27 Cunningham D, Starling N, Rao S, Iveson T, Nicolson M, Coxon F, Middleton G, Daniel F, Oates J, Norman AR, Upper Gastrointestinal Clinical Studies Group of the National Cancer Research Institute of the United Kingdom: Capecitabine and oxaliplatin for advanced esophagogastric cancer. N Engl J Med 2008; 358:36-46.

28 Kang YK, Kang WK, Shin DB, Chen J, Xiong J, Wang J, Lichinitser M, Guan Z, Khasanov R, Zheng L, Philco-Salas M, Suarez T, Santamaria J, Forster G, McCloud PI:Capecitabine/ cisplatin versus 5-fluorouracil/cisplatin as first-line therapy in patients with advanced gastric cancer: a randomised phase III noninferiority trial. Ann Oncol 2009;20:666673.

-29 Okines AF, Norman AR, McCloud P, Kang YK, Cunningham D: Meta-analysis of the REAL-2 and ML17032 trials: evaluating capecitabine based combination chemotherapy and infused 5 -fluorouracil based combination chemotherapy for the treatment of advanced oesophago-gastric cancer. Ann Oncol 2009;20:1529-1534.

30 Tsuburaya A, Sakamoto J, Morita S, Kodera Y, Kobayashi M, Miyashita Y, Macdonald JS: A randomized phase III trial of post-operative adjuvant oral fluoropyrimidine versus sequential paclitaxel/oral fluoropyrimidine; and UFT versus S1 for T3/T4 gastric carcinoma: the Stomach Cancer Adjuvant MultiInstitutional Trial Group (SAMIT) Trial. Jpn J Clin Oncol 2005;35:672-675.

31 Miyashiro I, Furukawa H, Sasako M, Yamamoto S, Nashimoto A, Nakajima T, Kinoshita T, Kobayashi O, Arai K, The Gastric Cancer Surgical Study Group in the Japan Clinical Oncology Group: Randomized clinical trial of adjuvant chemotherapy with intraperitoneal and intravenous cisplatin followed by oral fluorouracil (UFT) in serosa-positive gastric cancer versus curative resection alone: final results of the Japan Clinical Oncology Group trial JCOG 9206-2. Gastric Cancer 2011;14: 212-218.

32 Kang YK, Ryoo BY, Chang HM, Zang DY, Kim TW, Yang DH, Jang SJ, Yook JH, Oh ST, Kim BS: Update of AMC 0101 study: a phase III trial of intraperitoneal cisplatin and early mitomycin-C plus long-term doxifluridine plus cisplatin (ice MFP) versus mitomycin-C plus short-term doxifluridine (Mf) as adjuvant chemotherapy for grossly serosa-positive advanced gastric cancer (NCT00296322). J Clin Oncol 2012;30(suppl 4):abstr 4.

33 Ohtsu A, Sasako M: Overview of adjuvant therapy for resected gastric cancer: differences in Japan and the United States. Semin Oncol 2005;32:S101-S104.

34 Lordick F, Siewert JR: Recent advances in multimodal treatment for gastric cancer: a review. Gastric Cancer 2005;8:78-85.

- 35 Kim S, Lim DH, Lee J, Kang WK, MacDonald JS, Park CH, Park SH, Lee SH, Kim K, Park
JO, Kim WS, Jung CW, Park YS, Im YH, Sohn TS, Noh JH, Heo JS, Kim YI, Park CK, Park K: An observational study suggesting clinical benefit for adjuvant postoperative chemoradiation in a population of over 500 cases after gastric resection with D2 nodal dissection for adenocarcinoma of the stomach. Int J Radiat Oncol Biol Phys 2005;63:1279-1285.

36 Lee J, Lim do H, Kim S, Park SH, Park JO, Park YS, Lim HY, Choi MG, Sohn TS, Noh JH, Bae JM, Ahn YC, Sohn I, Jung SH, Park CK, Kim KM, Kang WK: Phase III trial comparing capecitabine plus cisplatin versus capecitabine plus cisplatin with concurrent capecitabine radiotherapy in completely resected gastric cancer with D2 lymph node dissection: the ARTIST trial. J Clin Oncol 2012; 30:268-273.

37 Dikken JL, Jansen EP, Cats A, Bakker B, Hartgrink $\mathrm{HH}$, Kranenbarg EM, Boot $\mathrm{H}$, Putter $\mathrm{H}$, Peeters KC, van de Velde CJ, Verheij M: Impact of the extent of surgery and postoperative chemoradiotherapy on recurrence patterns in gastric cancer. J Clin Oncol 2010;28:24302436.

38 Ychou M, Boige V, Pignon JP, Conroy T, Bouché O, Lebreton G, Ducourtieux M, Bedenne L, Fabre JM, Saint-Aubert B, Genève J, Lasser P, Rougier P: Perioperative chemotherapy compared with surgery alone for resectable gastroesophageal adenocarcinoma: an FNCLCC and FFCD multicenter phase III trial. J Clin Oncol 2011;29:1715-1721.

39 Schuhmacher C, Gretschel S, Lordick F, Reichardt P, Hohenberger W, Eisenberger CF, Haag C, Mauer ME, Hasan B, Welch J, Ott K, Hoelscher A, Schneider PM, Bechstein W, Wilke H, Lutz MP, Nordlinger B, Van Cutsem E, Siewert JR, Schlag PM: Neoadjuvant chemotherapy compared with surgery alone for locally advanced cancer of the stomach and cardia: European Organisation for Research and Treatment of Cancer randomized trial 40954. J Clin Oncol 2010;28:5210-5218.

40 Okines A, Verheij M, Allum W, Cunningham D, Cervantes A, ESMO Guidelines Working Group: Gastric cancer: ESMO Clinical Practice Guidelines for diagnosis, treatment and follow-up. Ann Oncol 2010;21(suppl 5):v50v54.

41 NCCN: NCCN Clinical Practice Guidelines in Oncology. Gastric Cancer. Version 2. 2011. http://www.nccn.org.

42 Fujitani K, Sasako M, Iwasaki Y, Yoshimura K, Sano T, Nashimoto A, Fukushima N, Arai K, Kinoshita T, Kobayashi O, Tanemura H: A phase II study of preoperative chemotherapy (CX) with S-1 and cisplatin followed by gastrectomy for clinically resectable type 4 and large type 3 gastric cancer: JCOG 0210. J Clin Oncol 2007;25(18S):abstr 4609.

43 Yoshikawa T, Sasako M, Yamamoto S, Sano T, Imamura H, Fujitani K, Oshita H, Ito S, Kawashima Y, Fukushima N: Phase II study of neoadjuvant chemotherapy and extended surgery for locally advanced gastric cancer. $\mathrm{Br}$ J Surg 2009;96:1015-1022. 
44 Yoshikawa T, Nakamura K, Tsuburaya A, Sano T, Mizusawa J, Katai H, Kurita A, Uyama I, Nomura E, Sasako M, Gastric Cancer Surgical Study Group of Japan Clinical Oncology Group: A phase II study of preoperative chemotherapy with S-1 (S) and cisplatin (P) followed by D3 gastrectomy for gastric cancer (GC) with extensive lymph node metastasis (ELM): survival results of JCOG 0405. J Clin Oncol 2011;29(suppl 4):abstr 70.

45 Tsuburaya A, Katayama H, Mizusawa J, Nakamura K, Katai H, Imamura H, Nashimoto A, Fukushima N, Sano T, Sasako M, The Gastric Cancer Surgical Study Group of JCOG: An integrated analysis of two phase II trials (JCOG0001 and JCOG0405) of preoperative chemotherapy followed by D3 gastrectomy for gastric cancer (GC) with extensive lymph node metastasis (ELM). J Clin Oncol 2011; 29(suppl 4):abstr 90.

46 Yoshikawa T, Omura K, Kobayashi O, Nashimoto A, Takabayashi A, Yamada T, Yamaue H, Fujii M, Yamaguchi T, Nakajima T: A phase II study of preoperative chemotherapy with S-1 plus cisplatin followed by D2/D3 gastrectomy for clinically serosa-positive gastric cancer (JACCRO GC-01study). Eur J Surg Oncol 2010;36:546-551.

47 Ohnuma H, Sato Y, Takayama T, Sagawa T, Hirakawa M, Harada K, Nobuoka T, Hirata K, Sato Y, Takahashi Y, Katsuki S, Takahashi S, Hirayama M, Takahashi M, Maeda M, Sato T, Miyanishi K, Kobune M, Takimoto R, Kato J:
A phase II study of neoadjuvant combination chemotherapy with docetaxel, cisplatin, and S-1 for locally advanced gastric cancer. J Clin Oncol 2011;29(suppl 15):abstr 4057.

48 Sym SJ, Chang HM, Ryu MH, Lee JL, Kim TW, Yook JH, Oh ST, Kim BS, Kang YK: Neoadjuvant docetaxel, capecitabine and cisplatin (DXP) in patients with unresectable locally advanced or metastatic gastric cancer. Ann Surg Oncol 2010;17:1024-1032.

49 Inoue T, Yachida S, Usuki H, Kimura T, Hagiike M, Okano K, Suzuki Y: Pilot feasibility study of neoadjuvant chemoradiotherapy with S-1 in patients with locally advanced gastric cancer featuring adjacent tissue invasion or JGCA bulky N2 lymph node metastases. Ann Surg Oncol 2012;19:2937-2945. 